\title{
Electrochemical sensing method for point-of-care cortisol detection in human immunodeficiency virus-infected patients
}

This article was published in the following Dove Press journal:

International Journal of Nanomedicine

19 January 2015

Number of times this article has been viewed

\author{
Ajeet Kaushik' \\ Adriana Yndart ${ }^{1}$ \\ Rahul Dev Jayant' \\ Vidya Sagar ${ }^{\prime}$ \\ Venkata Atluri' \\ Shekhar Bhansali ${ }^{2}$ \\ Madhavan Nairl \\ 'Center of Personalized \\ Nanomedicine, Institute of Neuroimmune \\ Pharmacology, Department of \\ Immunology, Herbert Wertheim \\ College of Medicine, Florida International \\ University, ${ }^{2}$ BioMEMS Microsystems \\ Laboratory, Department of Electrical \\ and Computer Engineering, Florida \\ International University, Miami, FL, USA
}

\begin{abstract}
A novel electrochemical sensing method was devised for the first time to detect plasma cortisol, a potential psychological stress biomarker, in human immunodeficiency virus (HIV)-positive subjects. A miniaturized potentiostat (reconfigured LMP91000 chip) interfaced with a microfluidic manifold containing a cortisol immunosensor was employed to demonstrate electrochemical cortisol sensing. This fully integrated and optimized electrochemical sensing device exhibited a wide cortisol-detection range from $10 \mathrm{pg} / \mathrm{mL}$ to $500 \mathrm{ng} / \mathrm{mL}$, a low detection limit of $10 \mathrm{pg} / \mathrm{mL}$, and sensitivity of $5.8 \mu \mathrm{A}(\mathrm{pg} \mathrm{mL})^{-1}$, with a regression coefficient of 0.995 . This cortisol-selective sensing system was employed to estimate plasma cortisol in ten samples from HIV patients. The electrochemical cortisol-sensing performance was validated using an enzyme-linked immunosorbent assay technique. The results obtained using both methodologies were comparable within $2 \%-5 \%$ variation. The information related to psychological stress of HIV patients can be correlated with disease-progression parameters to optimize diagnosis, therapeutic, and personalized health monitoring.
\end{abstract}

Keywords: psychological stress, personalized health care, cortisol, HIV, electrochemical immunosensing, miniaturized sensing device

\section{Introduction}

Progression of human immunodeficiency virus (HIV) infection leads to life-threatening diseases, such as acquired immunodeficiency syndrome (AIDS). ${ }^{1-3}$ Progress in HIV infection is characterized as a function of immune system impairments wherein various stress factors, such as cortisol, play a significant role in diseases progression and diagnosis. ${ }^{1-7}$ HIV infection activates the hypothalamic production and secretion of corticotropin-releasing hormone. This in turn causes the release of cytokine inflammatory response against viral infection, which stimulates the hypothalamuspituitary-adrenal axis. This immunomodulation generates psychological stress that activates the corticotropic axis. HIV patients exhibit increased glucocorticoid-receptor expression and reduced substrate-binding affinity, which increases plasma cortisol and correlates with adrenocorticotropic hormone levels, affecting adrenal sufficiency. ${ }^{1,2}$ The hypothesis related to cortisol secretion and its relation with sensitized behavior in HIV-infected patients is illustrated in Figure $1 .{ }^{8}$

However, there is no clear evidence to prove the existence of a correlation between cortisol levels and HIV-infection stages. ${ }^{9}$ Higher plasma cortisol levels have been observed more in untreated HIV-positive patients compared to treated patients. ${ }^{5}$ Besides this, a negative correlation between CD4 cell count and plasma cortisol levels has also been reported. ${ }^{2,5,8}$ It appears that cortisol contributes to suppression of beneficial activity of T-helper (Th)-1 cytokines in favor of Th2 cytokines (eg, IL-4, IL-6, and IL-10), 


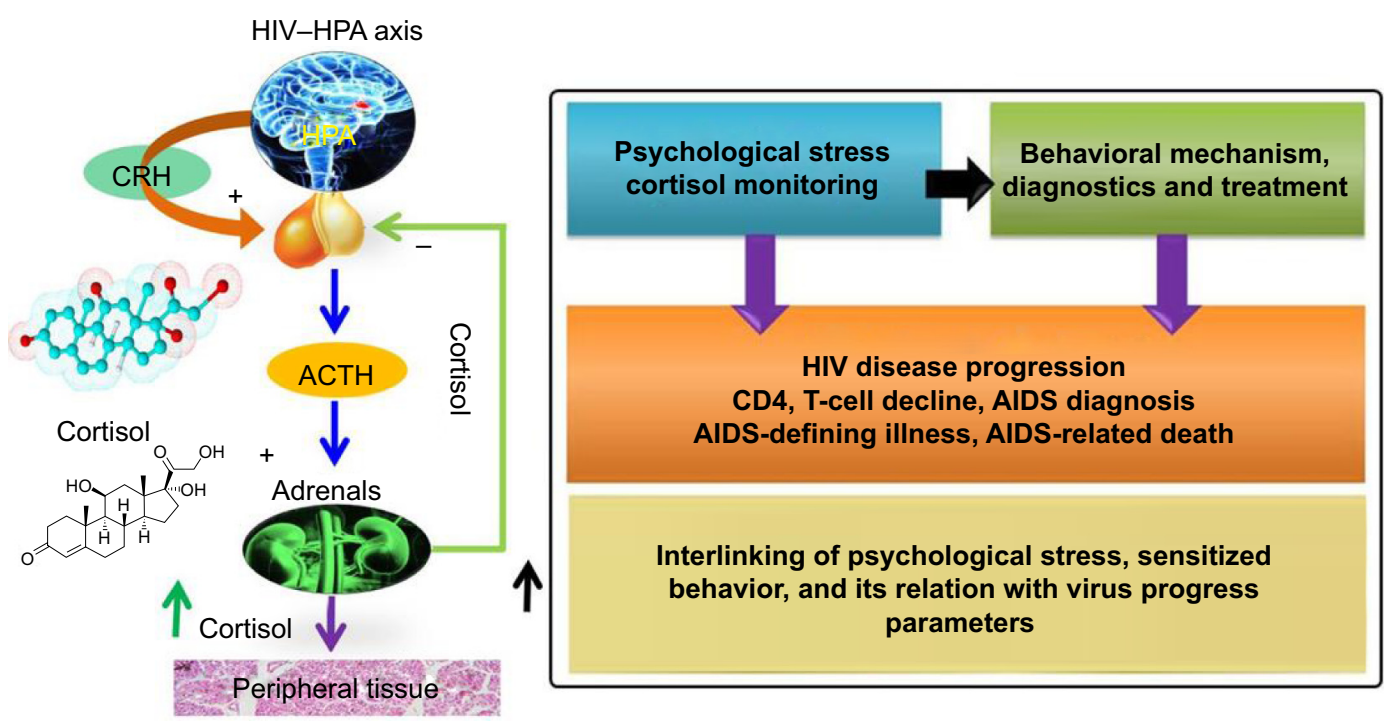

Figure I Schematic illustration of HPA axes in HIV progression. In cases of HIV, there is impaired adrenal reverse and more peripheral glucocorticoid excess. Abbreviations: HPA, hypothalamus-pituitary-adrenal; HIV, human immunodeficiency virus; $\mathrm{CRH}$, corticotropin-releasing hormone; ACTH, adrenocorticotropic hormone; AIDS, acquired immunodeficiency syndrome.

and hence leads to greater HIV progression. Recently, many studies have reported the significance of cortisol detection and its correlation with different diseases. ${ }^{3,7,10-13}$ Therefore, diurnal cortisol detection in the laboratory and at the point of care (POC) has a great impact in monitoring sensitized/ altered human behavior. ${ }^{11,12}$ Diurnal cortisol circadian rhythm is affected by schedule/activity and psychological/emotional stress of individuals. Cortisol abnormalities depress the immune system and lead to Cushing's disease, Addison's disease, and posttraumatic disorder. ${ }^{11,12}$ The enzyme-linked immunosorbent assay (ELISA) is the most reliable classical method to detect cortisol levels in patient samples. This method is limited to the laboratory, due to its requirements of longer measurement time, complex sample processing, expert man power, and sensing limitation to high concentrations ( $\mathrm{ng} / \mathrm{mL}$ or more). Therefore, cortisol detection in patients at the clinic or POC is in demand to understand diurnal behavioral patterns of individual subjects. ${ }^{14}$

Due to its salient features, such as fast, selective, and sensitive detection, an electrochemical cortisol-immunosensing methodology is being rapidly adopted for cortisol detection at the $\mathrm{pg} / \mathrm{mL}$ level. ${ }^{11-13}$ The introduction of nano/microelectrodes, nanostructured sensing materials, microelectronics, and miniaturized sensing transducers in sensor fabrication have been shown to improve device performance. ${ }^{11,12,15-19}$ The integration of a cortisol sensor with a microfluidic system and a miniaturized potentiostat (M-P) has been reported to monitor cortisol with reduced form factors. ${ }^{11,18,20}$ Further, efforts are being made to develop these sensing systems at POC levels for personalized health monitoring. ${ }^{14,18,21-23}$ Electrochemical immunosensors based on self-assembled monolayers (SAMs) and nanostructures have been reported to detect cortisol, but their application in real sample analysis is currently limited. ${ }^{16-18}$ Therefore, there is an urgent need to establish an electrochemical sensing protocol for detecting cortisol in desired fluids, such as plasma, blood, saliva, urine, and interstitial fluid, of patients at the POC.

In this current research, we illustrate the integration of an electrochemical sensing device capable of performing cyclic voltammetry (CV) to detect plasma cortisol levels in HIV-positive patients. We validated the performance of the developed method by ELISA, and sensing performance was in correlation within $2 \%-5 \%$ variation. Therefore, in conclusion we say that this method can be adopted as a part of stress management, specifically for personalized health care monitoring of HIV-positive patients.

\section{Materials and methods}

Fabrication of electrochemical

\section{immunosensor}

Dithiobis(succinimidyl propionate) (DTSP), sodium borohydride $\left(\mathrm{NaBH}_{4}\right)$, monoclonal anticortisol antibody (anti- $\mathrm{C}_{\mathrm{ab}}$ ), cortisol, and other chemicals were purchased from SigmaAldrich, and were used without any further purification. Phosphate-buffered saline (PBS) solution (10 mM, pH 7.4) was prepared by dissolving one PBS tablet in $200 \mathrm{~mL}$ 
of deionized (DI) water and used to prepare the anti- $\mathrm{C}_{\mathrm{ab}}$ $(1 \mathrm{mg} / \mathrm{mL})$ and cortisol concentrations.

The detailed experimental process related to electrochemical cortisol sensor fabrication was described in our previous publications in detail. ${ }^{18,24} \mathrm{We}$ employed an electrochemically cleaned interdigitated gold microelectrode (IDE-Au; chamber volume $\sim 5 \mu \mathrm{L}$, electrode width and electrode gap $10 \mu \mathrm{m}$ ), which were dispersed in a $2 \mathrm{mg} / \mathrm{mL}$ solution of DTSP (reduced using $\mathrm{NaBH}_{4}[10 \mathrm{mg} / \mathrm{mL}$ in DI water]) for 2 hours to prepare SAMs. The unbound DTSP particles on the electrode surface were washed with acetone, and final washing was done with DI water. For electrochemical immunosensor fabrication, $5 \mu \mathrm{L}$ of anti- $\mathrm{C}_{\mathrm{ab}}(1 \mathrm{mg} / \mathrm{mL}$ ) was covalently immobilized (for 2 hours) onto a DTSP-SAM/IDE-Au electrode via amide-bond formation between the amine group of antibodies and the reactive succinimidyl group of the DTSP. Anti-C $\mathrm{ab}_{\mathrm{ab}}$ DTSP-SAM/ IDE-Au bioelectrodes were washed using PBS ( $\mathrm{pH} 7.4,10$ $\mathrm{mM}$ ) to remove any unbound molecules. Ethanolamine (EA, $5 \mu \mathrm{L}$ of $2 \mathrm{mg} / \mathrm{mL}$ ) was immobilized on the anti- $\mathrm{C}_{\mathrm{ab}} / \mathrm{DTSP} /$ IDE-Au bioelectrode for 10 minutes to bind the nonspecific site of the immunoelectrode, followed by washing using DI water. Finally, EA/anti-C $\mathrm{ab}_{\mathrm{b}} / \mathrm{DTSP} / \mathrm{IDE}-\mathrm{Au}$ immunoelectrodes were stored in a refrigerator at $4^{\circ} \mathrm{C}$ when not in use.

\section{Design of LTCC-based microfluidic manifold}

A low temperature co-fired ceramic (LTCC) microfluidic architecture was utilized, which consisted of two microchannels. Both channels were connected to a reaction chamber placed on top of a biosensor chip. These channels were used for sample-in and waste-out processes using a three-way solenoid fluidic valve. During sensing, the washing step is crucial to avoid contamination and nonspecific moieties from the sensor surface. To obtain optimum washing efficiency, a computational fluid dynamic approach via Comsol Multiphysics ${ }^{\circledR}$ software was used to characterize fluid-flow profiles. The details of the design optimization of the LTCC microfluidic manifold were published in our previous report. ${ }^{18}$ The LTCC microfluidic chip consists of three layers of green tape (DuPont 951). The bottom layer is a reaction chamber $(5 \mathrm{~mm}$ diameter and volume of $10 \mu \mathrm{L})$ that interfaces with the sensor. The middle layer has an inlet and outlet microchannels for the navigation of sample/buffer/ waste. The top layer covers the microchannels and ports for incorporating fluidic connectors. Green tapes were patterned using a computer-controlled $10.6 \mu \mathrm{m} \mathrm{CO}_{2}$ laser with a spot size of $35 \mu \mathrm{m}$. Further, the patterned tape was aligned to be laminated using an isostatic hot press (Phi-Tulip) at $150^{\circ} \mathrm{C}$ for 15 minutes at 3,000 psi pressure. The aligned laminated green tape layers were fused to the LTCC through heating at $850^{\circ} \mathrm{C}$ in the presence of oxygen. Tygon tubing was connected at an inlet and outlet port of the microfluidic manifold via polydimethylsiloxane (Dow Corning). The fluids were introduced into the device via a programmable two-syringe pump network (New Era Pumps). A fabricated microfluidic device containing a biosensor chip was integrated with an acrylic fixture for portability. The final device was connected with an M-P for electrochemical measurement. ${ }^{18}$

During measurement, $10 \mu \mathrm{L}$ of each sample was introduced in the inlet channel at a flow rate of $10 \mu \mathrm{L} / \mathrm{min}$. The sample was incubated on immunosensor electrodes (static condition) for 30 minutes for the completion of the antigenantibody reaction. Further, the washing buffer solution $(30 \mu \mathrm{L})$ was then introduced into the reaction chamber $(10 \mu \mathrm{L} / \mathrm{min}$ for 3 minutes) to remove unbound moieties. For electrochemical experiments, $5 \mu \mathrm{L}$ of measurement buffer (PBS, $\mathrm{pH}$ 7.4) containing $5 \mathrm{mM} \mathrm{Fe}(\mathrm{II}) / \mathrm{Fe}(\mathrm{III})$ as redox moieties was allowed to flow in the reaction chamber. Solenoid three-way valves (Lee) were utilized for the successful flow of samples and buffer.

\section{Design of miniaturized potentiostat}

A schematic illustration of the electrochemical cortisolimmunosensing protocol, preparation of the immunosensor, architecture of the LTCC-based microfluidic manifold, reconfigured M-P chip (LMP9100) for electrochemical measurement, and comparison of M-P-obtained CV curve of IDE with a conventional potentiostat is shown in Figure 2. The details related to the preparation of the M-P have been explained in our previous work. ${ }^{14}$ In brief, the LMP91000 board was procured from Texas Instruments and reconfigured to design an M-P capable of performing full-range $\mathrm{CV}$ measurement using a three-electrode system. For CV measurements using the LMP91000, an external central processing unit with SensorAFE Designer software was connected with a USB communication feature. A BeagleBone microcontroller unit was added to make the device portable. To enable the communication, the LMP91000EVM was powered and controlled by the microcontroller via the $\mathrm{I}^{2} \mathrm{C}$ interface.

To achieve three-electrode-based electrochemical measurements, we removed the two-wire jumper pin and connected a J_MENB jumper to enable manual operation mode. A reconfigured LMP91000EVM generated an output voltage proportional to the current flowing through the working electrode. 


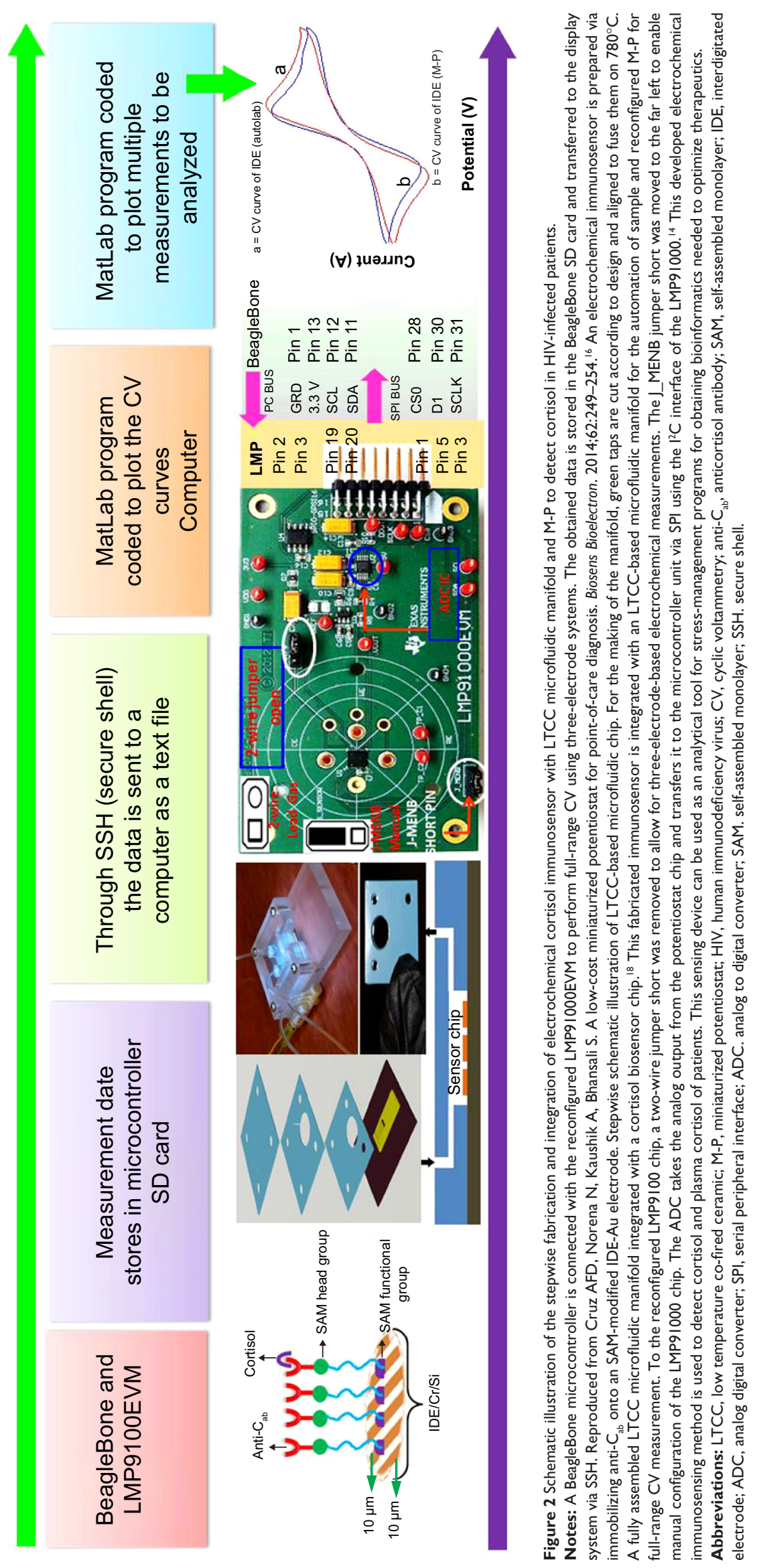


This voltage was provided by the transimpedance amplifier at the output stage. The acquisition of the signal response of the potentiostat was sent back to the microcontroller through the serial peripheral interface of the ADC161S626 analog digital converter (embedded on the LMP91000EVM). On applying optimized programming, the LMP91000EVM performed CV as a function of varying scan-rate potential in the range from $-0.6 \mathrm{~V}$ to $0.6 \mathrm{~V}$. The output voltage of the LMP91000EVM is proportional to the cell current. This can be obtained by plugging the output voltage of the LMP91000EVM in the transimpedance-amplifier transfer-function equation, taking into consideration the parameters set for the $\mathrm{CV}$ measurement using the equation:

$$
I_{\text {out }}=\frac{V_{\text {out }}-V_{I N T-Z}}{T I A_{\text {gain }}}
$$

The electrochemical performance of the Au-IDE based on $\mathrm{CV}$ using the M-P was comparable with the results obtained using a Metrohm Autolab potentiostat, thus validating M-P performance. ${ }^{16}$

\section{Electrochemical measurement}

$\mathrm{CV}$-based electrochemical measurements using the M-P at a scan rate of $50 \mathrm{mV} / \mathrm{s}$ in $5 \mu \mathrm{L}$ of PBS (pH 7.4) containing $5 \mathrm{mM}\left(\mathrm{Fe}[\mathrm{CN}]_{6}\right)^{3-/ 4-}$ as redox moieties in a potential range from -0.6 to $0.6 \mathrm{~V}$ were conducted to characterize sensor fabrication and to detect cortisol concentrations. To retain high biological activity of biomolecules, a $\mathrm{pH}$ of 7.4 for the PBS was chosen. This was attributed to the fact that this is the optimum $\mathrm{pH}$ selected for electrochemistry of immunosen-

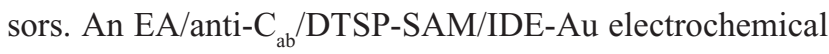
immunosensor was used to detect cortisol in plasma samples of HIV-positive patients.
Plasma sample collection of HIV patients

Blood donors were apprised of this study, and their consent was obtained consistent with the policies of Florida International University (FIU) and the National Institutes of Health (NIH). The study protocol was approved by the institutional review board of FIU. HIV-infected patients were recruited from the Borinquen Health Care Center, Miami. Patients were males and females. All vital clinical information, ie, race, sex, drug therapy, and CD4 levels of each available HIV patient $(n=10)$, obtained from the hospital is summarized in Table 1. The identities of all the subjects recruited were kept confidential. Blood from the donors to be processed as plasma was directly drawn into blood-collection tubes containing the anticoagulant K2 ethylenediaminetetraacetic acid (BD; Fisher Scientific; catalog number 366643). Following collection, all plasma samples were centrifuged immediately for 15 minutes at 5,000 $\mathrm{g}$ at $4^{\circ} \mathrm{C}$, and supernatants were carefully collected.

Plasma cortisol samples were stored at $-20^{\circ} \mathrm{C}$ to maintain their biological activity. All the samples were defrosted to room temperature for further use to detect cortisol concentration using electrochemical immunosensors and ELISA. A cortisol (human) ELISA kit was procured form Abnova Assays, and a standard protocol was adopted to estimate plasma cortisol. In brief, $50 \mu \mathrm{L}$ of 1:3 PBS diluted plasma cortisol samples of all patients were used for ELISA measurements.

\section{Results and discussion}

\section{Electrochemical studies of cortisol sensor} The reconfigured LMP91000-based M-P chip was utilized to characterize electrochemical immunosensor fabrication and cortisol-sensing performance. The electrochemical

Table I Patient demographics

\begin{tabular}{|c|c|c|c|c|c|}
\hline $\begin{array}{l}\text { Patient } \\
\text { identification }\end{array}$ & $\begin{array}{l}\text { Age } \\
\text { (years) }\end{array}$ & Sex (ethnicity) & $\begin{array}{l}\text { HIV status (year } \\
\text { of diagnosis) }\end{array}$ & $\begin{array}{l}\text { Antiretroviral } \\
\text { drugs }\end{array}$ & CD4 level \\
\hline 358 & 26 & Male (African-American) & Positive (1998) & Yes & 363 \\
\hline 261 & 35 & Male (African-American) & Positive $(2010)$ & Yes & 624 \\
\hline 398 & 41 & Male (Caucasian) & Positive (2004) & Yes & 235 \\
\hline 377 & 44 & Male (African-American) & Positive (2005) & Yes & 134 \\
\hline 250 & 45 & Male (African-American) & Positive (I996) & Yes & 671 \\
\hline 256 & 46 & Male (African-American) & Positive $(2010)$ & Yes & 326 \\
\hline 486 & 48 & Male (African-American) & Positive (1999) & Yes & 700 \\
\hline 202 & 50 & Male (African-American) & Positive (1995) & Yes & 237 \\
\hline 487 & 43 & Female (African-American) & Positive (2002) & Yes & 654 \\
\hline 405 & 49 & Female (African-American) & Positive (I993) & Yes & 608 \\
\hline
\end{tabular}

Abbreviation: HIV, human immunodeficiency virus. 
response study of the IDE-Au electrode (curve a), DTSP$\mathrm{SAM} / \mathrm{IDE}-\mathrm{Au}$ electrode (curve b), anti-C $\mathrm{ab}_{\mathrm{b}} / \mathrm{DTSP}-\mathrm{SAM} /$ IDE-Au immunoelectrode (curve c), EA/anti-C ${ }_{\mathrm{ab}} / \mathrm{DTSP}-$ $\mathrm{SAM} / \mathrm{IDE}-\mathrm{Au}$ immunoelectrode (curve d), and response change after adding cortisol on the immunosensor surface (curve e) is shown in Figure 3A. A detailed explanation of sensor fabrication, characterization, and optimization of operation parameters has been described in our previous publications. ${ }^{18,24}$ In brief, fabrication of DTSP-SAM onto electronically conducting IDE-Au hinders electron transport from electrolytes to the working electrode, due to the insulating nature of SAMs. This confirms the preparation of SAMs onto $\mathrm{Au}$ via thiol bonding. The electrochemical responsecurrent magnitude of DTSP-SAM/IDE-Au further decreased after immobilizing the anti- $\mathrm{C}_{\mathrm{ab}}$ via amide bonding. The presence of insulating anti- $\mathrm{C}_{\mathrm{ab}}$ on the surface caused hindrance in electron transport, thus confirming immobilization. The nonbinding sites of the anti- $\mathrm{C}_{\mathrm{ab}} / \mathrm{DTSP}-\mathrm{SAM} / \mathrm{IDE}-\mathrm{Au}$ immunoelectrode were blocked using EA. This also decreased the electrochemical response current, due to a reduction in electron transport from electrolytes to the IDE. The scan-rate-dependent $\mathrm{CV}$ of electrodes and bioelectrodes was also studied. A linear relationship between the magnitude of the electrochemical response current and the square root of the scan rate was observed (data not shown). This proved that the electrode surface was a linear diffusion-driven process. A linear relationship was also observed between the scan rate and potential differences, revealing facile electron transport from electrolytes to the working electrode surface.

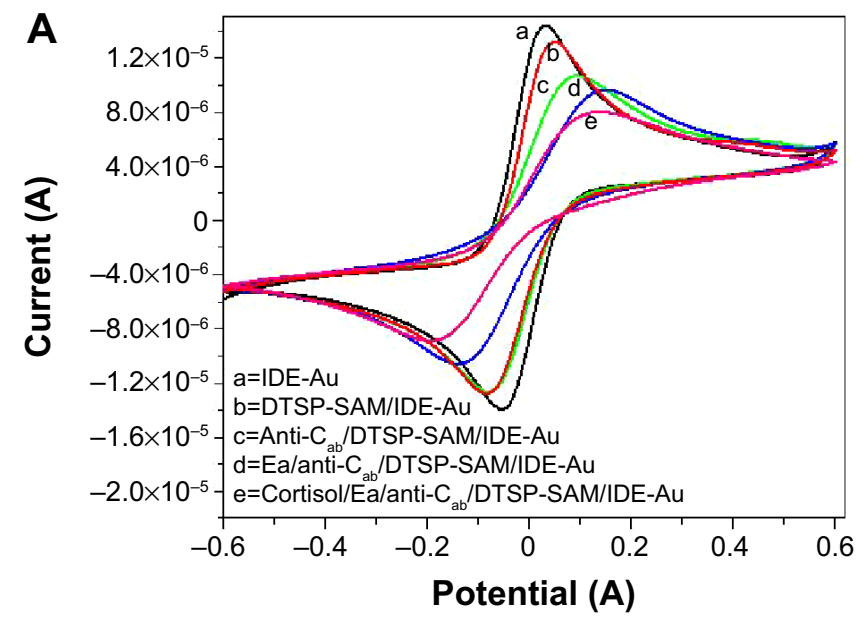

Electrochemical cortisol-immunosensing studies of the EA/anti-C ${ }_{\mathrm{ab}} / \mathrm{DTSP}-\mathrm{SAM} / \mathrm{IDE}-\mathrm{Au}$ sensor were performed as a function of cortisol concentration $(10 \mathrm{pg} / \mathrm{mL}$ to $500 \mathrm{ng} / \mathrm{mL})$ using M-P, as described in the Materials and methods section. Five microliters of each cortisol concentration was incubated on the sensor surface. An incubation time of 30 minutes was used to achieve optimum binding of the antibody and cortisol. Prior to electrochemical measurement, all immunoelectrodes were washed using $30 \mu \mathrm{L}$ of PBS ( $\mathrm{pH}$ 7.4) to remove the unbound cortisol. All the measurements were made in triplicate, and an average of these was used for cortisol-concentration estimation. A reduction in electrochemical response current was observed after the addition of each cortisol concentration. This was attributed to the insulating nature of the immunocomplex formed between anti- $\mathrm{C}_{\mathrm{ab}}$ and cortisol. This barrier layer inhibited the electron transport from electrolytes to the IDE-Au.

A calibration curve was plotted between the magnitude of current response and logarithm of cortisol concentration (Figure 3B). A linear-dependent relation was observed, which followed the equation:

\section{$Y=1.6 \times 10^{-5}+5.8 \times 10^{-6} \cdot \log ($ Cortisol concentration $):$ $R=0.995$}

The electrochemical cortisol immunosensor developed by us exhibited a wide linearity from $10 \mathrm{pg} / \mathrm{mL}$ to $500 \mathrm{ng} / \mathrm{mL}$ (on logarithmic scale), a low detection limit of $10 \mathrm{pg} / \mathrm{mL}$, and a sensitivity of $5.8 \mu \mathrm{A}(\mathrm{pg} \mathrm{mL})^{-1}$, with a regression

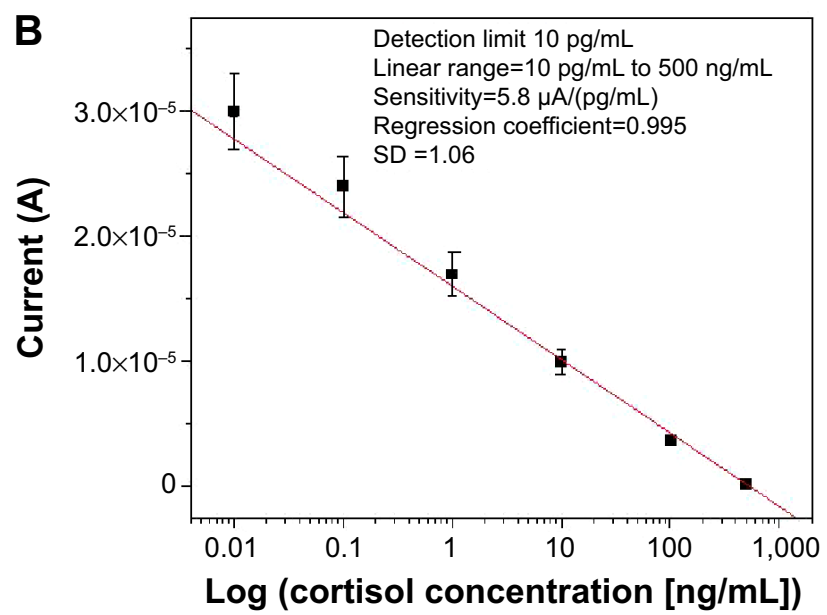

Figure 3 Electrochemical stepwise characterization of cortisol immunosensor and cortisol sensing calibration curve.

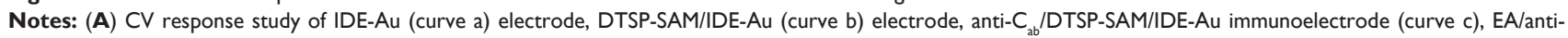
$\mathrm{C}_{\mathrm{ab}}$ /DTSP-SAM/IDE-Au immunoelectrode (curve d), and response change after adding cortisol on sensor surface (curve e). (B) A calibration curve was obtained using an electrochemical cortisol sensor as a function of cortisol concentrations ( $10-500 \mathrm{pg} / \mathrm{mL})$ on a logarithmic scale.

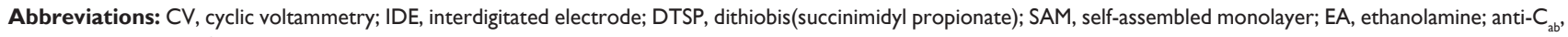
anticortisol antibody; SD, standard deviation. 
coefficient of 0.995 . The studies related to the selectivity and stability of this immunosensor have been discussed in our previous publications. ${ }^{18,24}$ The electrochemical response current of immunosensors using prostate specific antigen $(100 \mathrm{pg} / \mathrm{mL})$, neuron-specific enolase $(100 \mathrm{pg} / \mathrm{mL})$, Epidermal growth factor receptor $(100 \mathrm{pg} / \mathrm{mL})$, bovine serum albumin + cortisol $(100 \mathrm{pg} / \mathrm{mL})$, and cortisol $(100 \mathrm{pg} / \mathrm{mL})$ exhibited maximum change in the case of cortisol only. A variation of electrochemical response of $\sim 1 \%-2 \%$ in case of interferents and $\sim 14 \%$ with respect to cortisol was observed. This confirmed the selectivity of our developed cortisol immunosensor (data not shown). ${ }^{24} \mathrm{CV}$ studies related to the shelf life of the EA/anti- $\mathrm{C}_{\mathrm{ab}} /$ DTSP-SAM/IDE-Au immunoelectrode at intervals of 1 week revealed that the electrochemical sensor exhibited a response within 5\% variation and stability for 28 days (data not shown). ${ }^{24}$

\section{Electrochemical immunosensing of plasma cortisol}

For plasma cortisol analysis, the EA/anti-C ab $_{\text {DTSP-SAM/ }}$ IDE-Au immunosensor was utilized for detecting plasma cortisol concentrations in HIV-positive patients. A plasma sample $(5 \mu \mathrm{L})$ from each patient was incubated on the cortisol-immunosensor surface for 30 minutes. Further, the sensor surface was washed using $30 \mu \mathrm{L}$ of PBS (pH 7.4) to remove unbound plasma particles. The magnitude of the electrochemical response current of the EA/anti- $\mathrm{C}_{\mathrm{ab}} / \mathrm{DTSP}$ SAM/IDE-Au immunosensor was found to change after the addition of each plasma sample. The established calibration curve (Figure 3A) was used to estimate final cortisol concentration. All measurements were made in triplicate, and an average value was computed to estimate plasma cortisol concentration (Table 2). The obtained sensing performance as validated with ELISA technique is presented in Table 2.

\section{Plasma cortisol detection using ELISA}

The ELISA technique was performed using a 96-well titer plate with respect to six known concentrations $(20,50,100$, 200,400 , and $800 \mathrm{ng} / \mathrm{mL}$ ) to establish a calibration curve (Figure 4A). A detection limit of $1.5 \mathrm{ng} / \mathrm{mL}$, a detection range of $20-800 \mathrm{ng} / \mathrm{mL}$, a sensitivity of $50 \mathrm{ng} / \mathrm{mL}$ (Iab, intensity of absorbance), along with a regression coefficient of 0.989 and a standard deviation of \pm 1.06 , were achieved using an ELISA kit. The sensing-performance outcomes of both techniques are summarized in Table 3 . The obtained calibration curve was used to measure unknown plasma cortisol concentration in HIV-positive patient samples. All measurements were made in triplicate, and an average

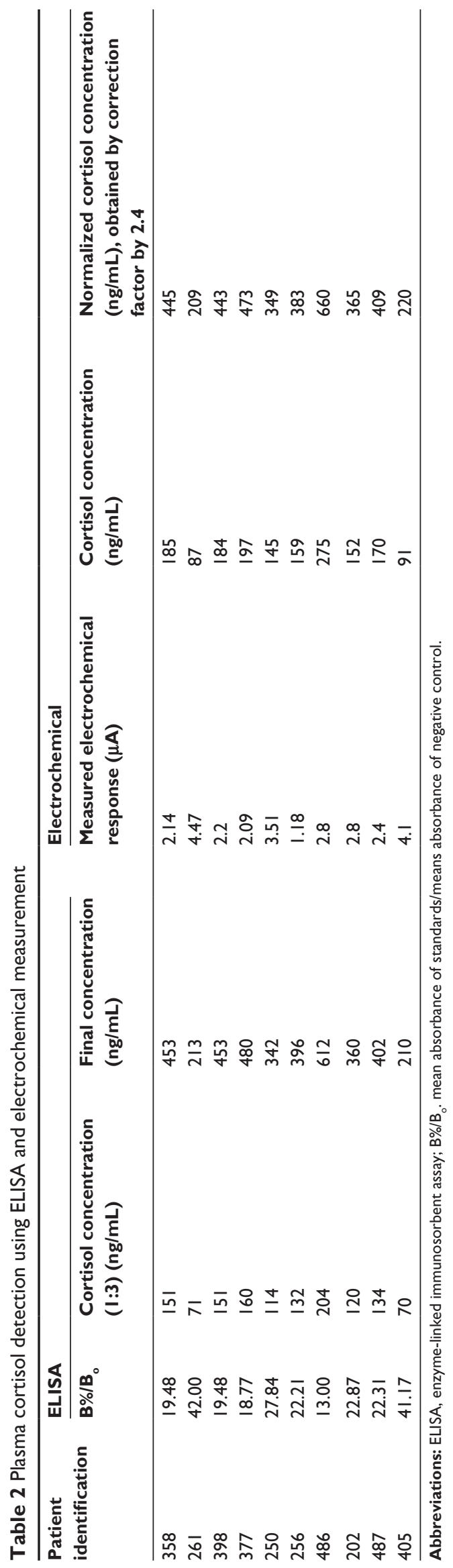



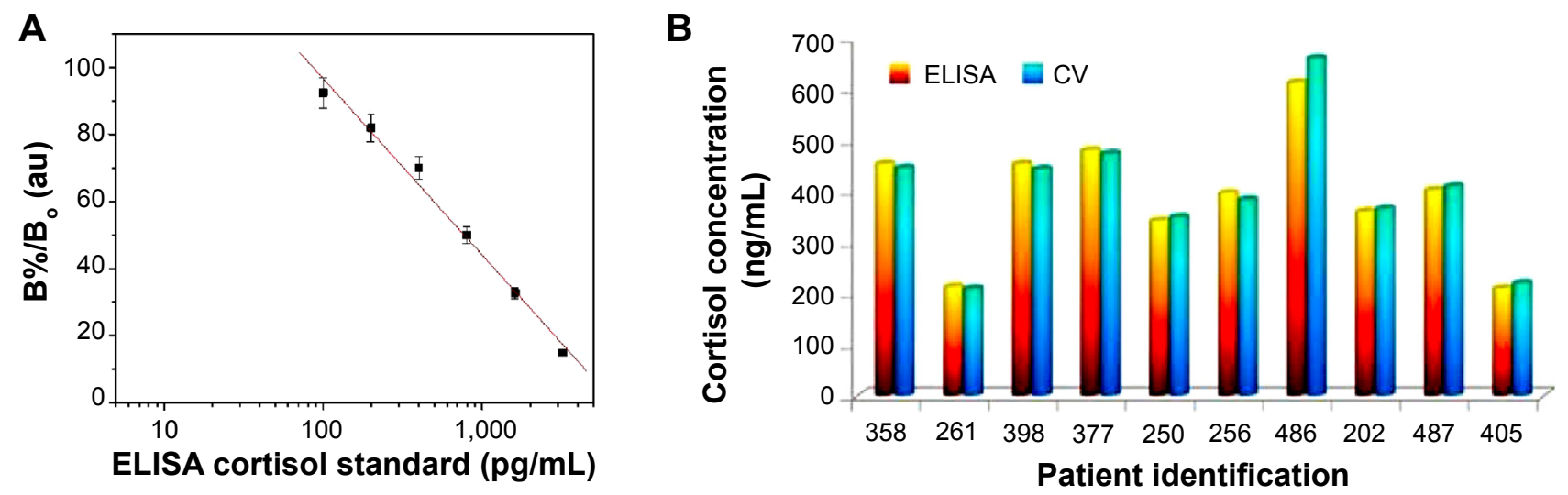

Figure 4 ELISA calibration curve to estimate plasma cortisol concentration and comparisons of plasma cortisol concentrations of HIV positive patients estimated using ELISA and $\mathrm{CV}$ method.

Notes: (A) Calibration plot obtained using ELISA techniques to detect plasma cortisol concentrations in HIV-positive patient. (B) A comparison of plasma cortisol of cocaine using HIV patients using ELISA and CV methods.

Abbreviations: ELISA, enzyme-linked immunosorbent assay; HIV, human immunodeficiency virus; CV, cyclic voltammetry; B\%/B . mean absorbance of standards/means absorbance of negative control; au, arbitrary unit.

value was utilized to estimate the final concentration, as shown in Table 2. A comparison of plasma cortisol level estimated using ELISA and electrochemical immunosensor is presented in Figure 4B.

The transduction techniques, ie, mode of output response, of ELISA ( $\left.\mathrm{I}_{\mathrm{Iab}}\right)$ and the electrochemical immunosensor (A) are different in nature of principle. Thus, obtained outcomes were in different magnitudes for each concentration. To establish a correlation for comparison between both techniques, the electrochemically detected cortisol concentrations were normalized by a factor of 2.4. Both techniques showed comparable results with $2 \%-5 \%$ variation, thus confirming the validation of the electrochemical cortisol-immunosensing protocol. However, in our previous study, a correlation factor of 2.2 was established to validate the results obtained using an electrochemical EA/anti-Cab/DTSP-SAM/IDE-Au immunosensor and ELISA to detect salivary cortisol. ${ }^{24}$ This difference is due to the physiological variation of biological fluids, eg, saliva has free cortisol, and plasma also contains bound cortisol, ie, corticosteroid-binding globulin.

An established, well-correlated, and validated electrochemical immunosensing protocol enables the quantification of plasma cortisol, and has the potential to detect cortisol in other biologically relevant fluids, such as saliva and interstitial fluids.

\section{Conclusion}

In this work, we detected plasma cortisol levels in HIV-positive patient samples using an electrochemical immunosensing device. The investigated device, consisting of an M-P chip interfaced with an LTCC microfluidic manifold, demonstrated cortisol detection at the $\mathrm{pg} / \mathrm{mL}$ level with a sensitivity of $5.8 \mu \mathrm{A}(\mathrm{pg} \mathrm{mL})^{-1}$. The plasma cortisol of HIVpositive patients was also estimated successfully using the ELISA technique. The obtained results were in good correlation $(2 \%-5 \%)$ with those obtained using the investigated electrochemical sensor. This confirmed the validation of the developed method. Efforts are being made to coordinate with clinics and hospitals to increase the sample volume of HIVpositive patients. Higher sample volumes will be of use to understand the relation of diurnal cortisol variation of HIV patients with virus-infection progress. Such obtained information or findings can be correlated with clinical diagnostics of HIV patients for personalized health monitoring and to decide on therapeutics.

\section{Acknowledgments}

This work was supported by NIH grants RO1-DA027049, R21-MH 101025, RO1-MH085259, and RO1-DA 034547, and partially supported by NSF-NERC (1160483). The authors are also thankful to Dr Abhay Vasudev (Intel process

Table 3 Summary of cortisol-sensing performance using ELISA and miniaturized electrochemical cortisol sensing device

\begin{tabular}{lllll}
\hline Detection technique & Detection limit & Detection range & Sensitivity & Measurement time \\
\hline Electrochemical & $10 \mathrm{pg} / \mathrm{mL}$ & $10 \mathrm{pg} / \mathrm{mL}$ to $500 \mathrm{ng} / \mathrm{mL}$ & $5.8 \mu \mathrm{A}(\mathrm{pg} / \mathrm{mL})$ & $35 \mathrm{minutes}$ \\
ELISA & $1.5 \mathrm{ng} / \mathrm{mL}$ & $20-8,000 \mathrm{ng} / \mathrm{mL}$ & $50 \mathrm{I}_{\mathrm{ab}}(\mathrm{ng} / \mathrm{mL})$ & $\sim 12 \mathrm{hours}$ \\
\hline
\end{tabular}

Abbreviations: ELISA, enzyme-linked immunosorbent assay; $I_{a b}$, intensity of absorption. 
engineer) for his help in system design and Prof. Dinesh Sood for scientific discussion.

\section{Disclosure}

The authors report no conflicts of interest in this work.

\section{References}

1. Antoni MH. Stress management and psychoneuroimmunology in HIV infection. CNS Spectr. 2003;8(1):40-51.

2. Bons J, Moreau L, Lefebvre H. Adrenal disorders in human immunodeficiency virus (HIV) infected patients. Ann Endocrinol (Paris). 2013;74(5-6):508-514.

3. Patterson S, Moran P, Epel E, et al. Cortisol patterns are associated with T cell activation in HIV. PloS One. 2013;8(7):e63429.

4. Aoun S, Ramos E. Hypertension in the HIV-infected patient. Curr Hypertens Rep. 2000;2(5):478-481.

5. Brown TT. The effects of HIV-1 infection on endocrine organs. Best Pract Res Clin Endocrinol Metab. 2011;25(3):403-413.

6. Abbott M, Khoo SH, Hammer MR, Wilkins EGL. Prevalence of cortisol deficiency in late HIV disease. J Infect. 1995;31(1):1-4.

7. Djamshidian A, O'Sullivan SS, Papadopoulos A, et al. Salivary cortisol levels in Parkinson's disease and its correlation to risk behaviour. J Neurol Neurosurg Psychiatry. 2014;82(10):1107-1111.

8. George MM, Bhangoo A. Human immune deficiency virus (HIV) infection and the hypothalamic pituitary adrenal axis. Rev Endocr Metab Disord. 2013;14(2):105-112.

9. Crepaz N, Passin WF, Herbst JH, et al. Meta-analysis of cognitivebehavioral interventions on HIV-positive persons' mental health and immune functioning. Health Psychol. 2008;27(1):4-14.

10. Djamshidian A, Averbeck BB, Lees AJ, O’Sullivan SS. Clinical aspects of impulsive compulsive behaviours in Parkinson's disease. J Neurol Sci. 2011;310(1-2):183-188.

11. Kaushik A, Vasudev A, Arya SK, Pasha SK, Bhansali S. Recent advances in cortisol sensing technologies for point-of-care application. Biosens Bioelectron. 2014;53:499-512.

12. Singh A, Kaushik A, Kumar R, Nair M, Bhansali S. Electrochemical sensing of cortisol: a recent update. Appl Biochem Biotechnol. 2014;174(3):1115-1126.
13. Vabbina PK, Kaushik A, Pokhrel N, Bhansali S, Pala N. Electrochemical cortisol immunosensors based on sonochemically synthesized zinc oxide 1D nanorods and 2D nanoflakes. Biosens Bioelectron. 2015;63:124-130.

14. Cruz AFD, Norena N, Kaushik A, Bhansali S. A low-cost miniaturized potentiostat for point-of-care diagnosis. Biosens Bioelectron. 2014; 62:249-254.

15. Arya SK, Chornokur G, Venugopal M, Bhansali S. Antibody functionalized interdigitated micro-electrode (IDmE) based impedimetric cortisol biosensor. Analyst. 2010;135(8):1941-1946.

16. Arya SK, Chornokur G, Venugopal M, Bhansali S. Dithiobis(succinimidyl propionate) modified gold microarray electrode based electrochemical immunosensor for ultrasensitive detection of cortisol. Biosens Bioelectron. 2010;25(10):2296-2301.

17. Kaushik A, Vasudev A, Arya SK, Bhansali S. Mediator and label free estimation of stress biomarker using electrophoretically deposited $\mathrm{Ag} @ \mathrm{AgO}-$ polyaniline hybrid nanocomposite. Biosens Bioelectron. 2013;50:35-41.

18. Vasudev A, Kaushik A, Tomizawa Y, Norena N, Bhansali S. An LTCCbased microfluidic system for label-free, electrochemical detection of cortisol. Sens Actuators B Chem. 2013;182:139-146.

19. Loncaric C, Tang Y, Ho C, Parameswaran MA, Yu HZ. A USB-based electrochemical biosensor prototype for point-of-care diagnosis. Sens Actuators B Chem. 2012;161(1):908-913.

20. Srinivasan V, Pamula VK, Fair RB. An integrated digital microfluidic lab-on-a-chip for clinical diagnostics on human physiological fluids. Lab Chip. 2004;4(4):310-315.

21. Safavieh M, Ahmed MU, Sokullu E, Ng A, Braescu L, Zourob M. A simple cassette as point-of-care diagnostic device for naked-eye colorimetric bacteria detection. Analyst. 2014;139(2):482-487.

22. Tudos AJ, Besselink GA, Schasfoort RB. Trends in miniaturized total analysis systems for point-of-care testing in clinical chemistry. Lab Chip. 2001;1(2):83-95.

23. Weaver W, Kittur H, Dhar M, Di Carlo D. Research highlights: microfluidic point-of-care diagnostics. Lab Chip. 2014;14(12):1962-1965.

24. Pasha SK, Kaushik A, Vasudev A, Snipes SA, Bhansali S. Electrochemical immunosensing of saliva cortisol. $J$ Electrochem Soc. 2014;161(2):B3077-B3082
International Journal of Nanomedicine

\section{Publish your work in this journal}

The International Journal of Nanomedicine is an international, peerreviewed journal focusing on the application of nanotechnology in diagnostics, therapeutics, and drug delivery systems throughout the biomedical field. This journal is indexed on PubMed Central, MedLine, CAS, SciSearch ${ }^{\circledR}$, Current Contents ${ } /$ Clinical Medicine,

\section{Dovepress}

Journal Citation Reports/Science Edition, EMBase, Scopus and the Elsevier Bibliographic databases. The manuscript management system is completely online and includes a very quick and fair peer-review system, which is all easy to use. Visit http://www.dovepress.com/ testimonials.php to read real quotes from published authors. 